\title{
KAURENOIC ACID DETERMINATION IN EXTRACT, TINCTURE AND SYRUP OF Mikania glomerata BY HPLC-QQQ-MS/MS
}

\author{
Alan F. Canevari Moreira ${ }^{\mathrm{a}}$, Victor Rodrigues Alves ${ }^{\mathrm{b}}$, Gustavo A. Micke ${ }^{\mathrm{b}}$, Lucas M. Duarte ${ }^{\mathrm{a}}$, Nerilson M. Lima ${ }^{\mathrm{a}}$ and Marcone \\ A. L. de Oliveira ${ }^{a}, *$,i) \\ aDepartamento de Química, Instituto de Ciências Exatas, Universidade Federal de Juiz de Fora, 36036-330 Juiz de Fora - MG, Brasil \\ bDepartamento de Química, Centro de Ciências Físicas e Matemáticas, Universidade Federal de Santa Catarina, 88040-900 \\ Florianópolis - SC, Brasil
}

Recebido em 20/01/2020; aceito em 17/02/2020; publicado na web em 16/04/2020

\begin{abstract}
This work aims to develop a rapid and reliable method by HPLC-QqQ-MS/MS for identification and quantification of Kaurenoic acid (KA) in extract, tincture and syrup from Mikania glomerata. The developed method allows identifying and quantifying KA in complex samples obtained from extract marketed in pharmaceutical industry, a tincture prepared with the leaves from plant and two syrups purchased in the local market. The quantification was performed using standard addition calibration curve. An accurate method for Kaurenoic acid determination in M. glomerata samples was developed. The concentrations of KA found in M. glomerata were $0.19 \mathrm{mg} \mathrm{mL}^{-1}$ in the commercial extract, $0.93 \mathrm{mg} \mathrm{mL}^{-1}$ in the tincture, $3.00 \times 10^{-3} \mathrm{mg} \mathrm{mL}^{-1}$ in the syrup B and in syrup A was not possible to quantify due to the concentration is below the detection limit. Since most reports describe the quantification of the main active constituent (coumarin) and do not provide relevant information on the quantification of KA in these sample types (syrup and tincture), the developed method represents an excellent alternative for agile and efficient analysis of the KA in complex matrices from simple dilution.
\end{abstract}

Keywords: medicinal plants; Mikania glomerata; kaurenoic acid; method development; HPLC-QqQ-MS/MS.

\section{INTRODUCTION}

Mikania glomerata Spreng, popularly known in Brazil as "guaco", is a medicinal plant widely used in the treatment of colds and respiratory problems such as asthma, from which they are expected to have their bronchodilator, anti-inflammatory and antispasmodic actions. ${ }^{1}$

Extracts of M. glomerata with high Kaurenoic Acid (KA) content were effective to inhibit the development of Streptococcus mutans and also against other bacteria that cause endodontic infections. ${ }^{2}$ The ethanolic extract of M. glomerata has been used as an antiallergic and anti-inflammatory agent ${ }^{3}$ and the leaves hydro-alcoholic extract presents anti-hemorrhagic effect. ${ }^{4}$ Fierro et al. evaluated fractions obtained from ethanolic extract of M. glomerata for the antiallergic and anti-inflammatory properties, whose results showed that the fractions studied are effective in inhibiting immunological inflammation. ${ }^{3}$

Ent-kaur-16-en-19-oic acid or kaurenoic acid (KA) (Figure 1) is a diterpene from kauran class. This class of compounds has a rigid and tetracyclic skeleton. In plants, the KA is an intermediate of the biogenesis of gibberellins that is widespread among medicinal plants and is found in M. glomerata.$^{5-7}$

This terpene present a variety of biological properties such as antileishmanial, ${ }^{8}$ antimalarial, ${ }^{9}$ antimicrobial, ${ }^{10}$ in vitro cytotoxic

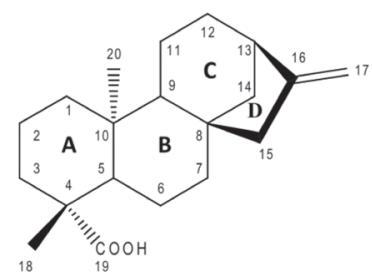

Figure 1. Structure of kaurenoic acid

*e-mail: marcone.oliveira@ufjf.edu.br potential and other important pharmacological effects have been described for KA and related kaurane terpenoids, mainly anti-platelet aggregation, ${ }^{11}$ analgesic and hypoglycemic activity. ${ }^{12}$

The scientific literature reports that methods have already been developed to evaluate KA from $M$. glomerata. A generic and timeconsuming HPLC-PDA method was developed to evaluate the main metabolites from M. glomerata, however, due to the limitations of the equipment, the method was used to analyze kaurane-type diterpenes of $M$. glomerata and was not specific to KA quantification in $M$. glomerata samples. ${ }^{13}$

In addition to the varieties of Mikania glomerata, other species such as M. laevigata are popularly known as "guaco" and are used in the treatment of diseases of the respiratory tract by the population. Therefore, the identification and quantification of chemical markers and other active principles from phytochemical extract are essential to ensure efficacy and confirm the use of the species as medicinal. ${ }^{14}$

Whereas the scientific literature shows few scientific studies to KA quantification in tinctures and syrup, and no specific method development for KA quantification and detection in tincture was found and most studies report methods with high time-consuming and also reports difficulties in the detection of kaurenoic acid in the specific ultraviolet regions, this study provides important information regarding the method development for quantification of this bioactive metabolite in these samples from medicinal plants.

Within this context, the present work proposes the development of a method for KA quantification by HPLC-QqQ-MS/MS to analyze samples of different complexities such as extracts, syrups and tinctures obtained from $M$. glomerata leaves. The analyzes by the method developed were faster than the methods available in the literature, since it is not necessary to dilute the samples in pre-established solvent, the samples are diluted in pure acetonitrile and injected in the equipment. The method developed in this work is innovative since was applied to different complex matrixes and exclusive for KA analysis. 


\section{EXPERIMENTAL}

\section{Materials}

Ultrapure water obtained from Mili- ${ }^{\circledR}$ purification system. Acetonitrile ultra-filtered grade HPLC J. T. Baker/Avantor brand (Xalostoc, Mexico). Absolute ethyl alcohol from Dinâmica brand (Diadema-SP, Brazil). Ultra-filtered methyl alcohol grade HPLC brand J. T. Baker was used (Avantor, Xalostoc, Mexico). KA isolated of the chloroform extract from tuberous roots of Smallanthus sonchifolius (Poepp \& Endl.), characterized structurally by ${ }^{1} \mathrm{H}$ NMR and ${ }^{13} \mathrm{C} \mathrm{NMR}$, kindly provided by Prof. Dr. Ademar Alves da Silva Filho from Federal University of Juiz de Fora (Juiz de Fora, Brazil) was used as analytical standard. Betulinic acid, purchased from Sigma-Aldrich Corporation, was used as analytical internal standard.

\section{Samples and extraction procedure}

Three types of samples were evaluated. Two sample types (extract and syrup) were obtained commercially with the appropriate specifications and the other sample (tincture) was prepared in the university laboratory.

For testing and evaluation of the developed method, herbal products were purchased from local drugstores: syrup of guaco (A) - a Mikania glomerata syrup standardized on coumarin $\left(0.0360 \mathrm{mg} \mathrm{mL}^{-1}\right)$, other syrup of guaco (B) - a Mikania glomerata syrup standardized on coumarin $\left(0.0882 \mathrm{mg} \mathrm{mL}^{-1}\right)$. Commercial extract of guaco, used as raw material by the pharmaceutical industry, whose composition is not declared.

Leaves of Mikania glomerata were collected on April 18, 2017, at 9:00 am, in the garden of the College of Pharmacy from Federal University of Juiz de Fora - UFJF. The plant was already identified by vegetable sample prepared in November 2006 and deposited in the CESJ - UFJF Leopoldo Krieger Herbarium.

The plant material (leaves) was stabilized and subjected to oven drying at $40{ }^{\circ} \mathrm{C}$ for 48 hours. After drying, the plant material was ground in knife mill and the tincture was prepared of $20 \mathrm{~g}$ of the plant material powder and an amount of ethanol $(70 \% \mathrm{w} / \mathrm{w})$ sufficient to complete $100 \mathrm{~mL}$. After that, 24 hours the filtration was carried out.

\section{HPLC-ESI-MS/MS conditions}

The LC-MS/MS analysis were performed using an Agilent 1200 series HPLC System (Waldboon, Germany) that consisted of a G1311A quaternary pump, G132A online degasser, and G1316A column oven. These were connected with an auto sampler manager (Model G1367). The system was coupled to an Applied Biosystems (Absciex) model 3200 Q Trap Triple Quadrupole Mass Spectrometer (Toronto, Canada) and an ESI source (TurboIonSpray). The ESI source was operated in negative ion mode. The mobile phase consisted of a gradient of water (A) and acetonitrile/water solution 95:5 v/v (B). The flow rate was maintained at $250 \mu \mathrm{L} \mathrm{min}^{-1}$ and the gradient profile was as follows: system preconditioning for $5 \mathrm{~min}$ with $50 \%$ B; 0-2.0 min: $50 \%$ B; 4.0 min: $95 \%$ B; 11.0 min: $95 \%$ B. The analyte separations were achieved on a Phenomenex Synergy $4 \mu$ Polar-RP 80 A 150x2.0 mm (4 $\mu \mathrm{m}$ particle size) and the injection volume was $5 \mu \mathrm{L}$. Data acquisition was performed with the MS Workstation by Analyst 1.6.2 software (AB/Sciex). Quantification was performed in SIM mode, maintaining the dwell time at $150 \mathrm{~ms}$. The ion transitions and the individual compound parameters, including the declustering potential (DP), entrance potential (EP), collision cell entrance potential (CEP), collision energy (CE), and cell exit potential (CXP), are summarized in Table 1.

The chromatography conditions were optimized and due to the selectivity provided by SIM monitoring.

The ion source parameters for ESI negative mode were as follows: CUR, 10 psi; CAD, set as medium pressure; IS, -4500 V; GS1, 45 psi; $\mathrm{GS} 2,45 \mathrm{psi}$; and temperature, $450^{\circ} \mathrm{C}$. High-purity nitrogen were used as the CUR, GS1, GS2, and CAD gases.

\section{Statistic evaluation}

To develop this method, various concentrations of authentic KA solution were prepared and had their analytical signals evaluated. For the quantification of Kaurenoic acid in the samples, the standard addition method considering calibration curves in four levels with genuine triplicates in each one of them was employed. This approach was defined due to the sample matrix complexity and also due to the impossibility to prepare a matrix free of KA. Calibration curves of KA were built, and the curves became linear in the tested range (from $0.00 \mathrm{mg} \mathrm{mL}^{-1}$ to $1.06 \mathrm{mg} \mathrm{mL}^{-1}$ ). The limit of detection (LOD) were evaluated by using $3.3 \sigma / \mathrm{S}$ and the limit of quantitation (LOQ) $10 \sigma / \mathrm{S}$, where $\sigma$ is the standard deviation of the response and $S$ is the slope of the sample calibration curves.

The standard addition method was applied to evaluate the selectivity of this method.

\section{RESULTS AND DISCUSSION}

\section{Analysis by RP-HPLC-PDA and mass spectrometry}

The developed method employed gradient elution in reversedphase in order to sample components analysis using a column of etherlinked phenyl phase. This column was specifically used to maximize retention and selectivity for analytes that show structural similarity with KA, with a wide apolar region and another polar region, as shown in Figure 1. This feature allows for improved polar retention that complements the more conventional $\mathrm{C} 18$ column chemistries, as well as provides improved peak shape and high selectivity for this kind of analyte.

Initially, a direct infusion of the standard was performed to evaluate the formed ions, however, no fragmentation of KA was observed. This lack of KA fragmentation was already expected according to studies reported in literature.

Then, this lack of KA fragmentation by ESI was applied in this work such as a unique feature for the detection of KA. The SIM mode was chosen to monitor the mass/charge ratio $(\mathrm{m} / \mathrm{z})$. This monitoring is usually done by the specific $\mathrm{m} / \mathrm{z}$, ratio products after the precursor ion fragmentation; however, since there was no fragmentation, the monitored $\mathrm{m} / \mathrm{z} 301\left([\mathrm{M}-\mathrm{H}]^{-}\right)$, was the same in the first quadrupole Q1 and in the last quadrupole Q3, even after the gradual elevation of the ionization energy from 0 to $60 \mathrm{eV}$ in the collision cell Q2. Due

Table 1. Parameters of each monitored transition obtained by direct infusion of Kaurenoic Acid and Betulinic Acid in MS equipment (*Dwell time)

\begin{tabular}{lcccccccc}
\hline Compound & Q1 $(\mathrm{Da})$ & $\mathrm{Q} 3(\mathrm{Da})$ & $\mathrm{t}^{*}(\mathrm{~ms})$ & $\mathrm{DP}(\mathrm{V})$ & $\mathrm{EP}(\mathrm{V})$ & $\mathrm{CEP}(\mathrm{V})$ & $\mathrm{CE}(\mathrm{V})$ & $\mathrm{CXP}(\mathrm{V})$ \\
\hline Kaurenoic acid & 301.0 & 301.0 & 150.0 & -55.0 & -4.5 & -16.0 & -8.0 & -4.0 \\
Betulinic acid & 455.0 & 455.0 & 150.0 & -55.0 & -4.5 & -16.0 & -8.0 & -4.0 \\
\hline
\end{tabular}



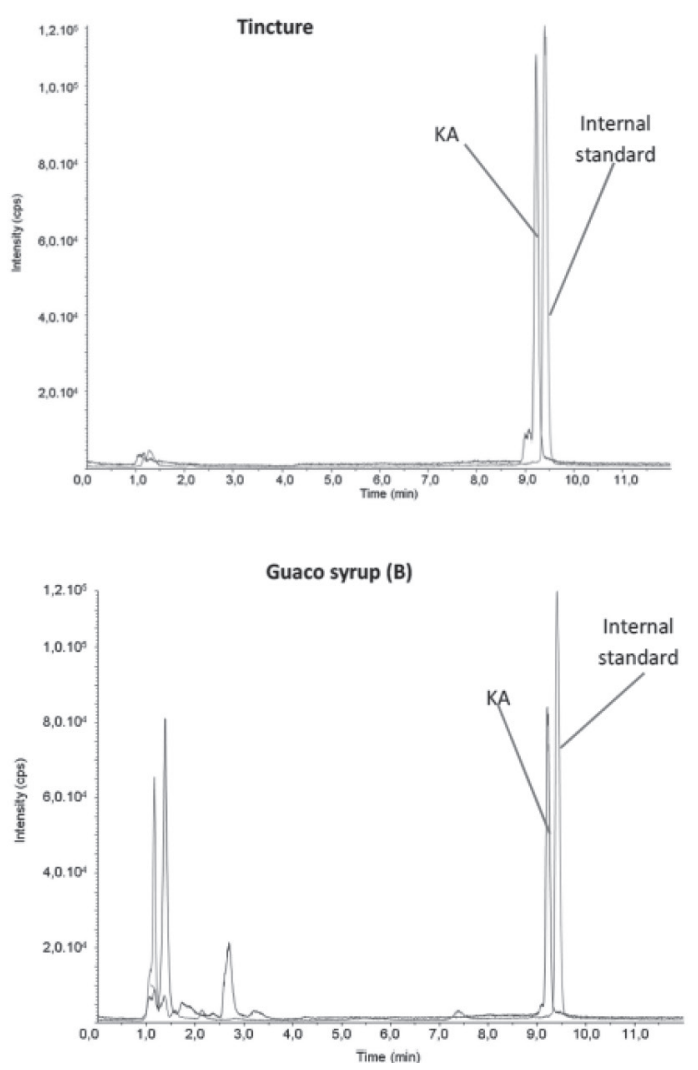
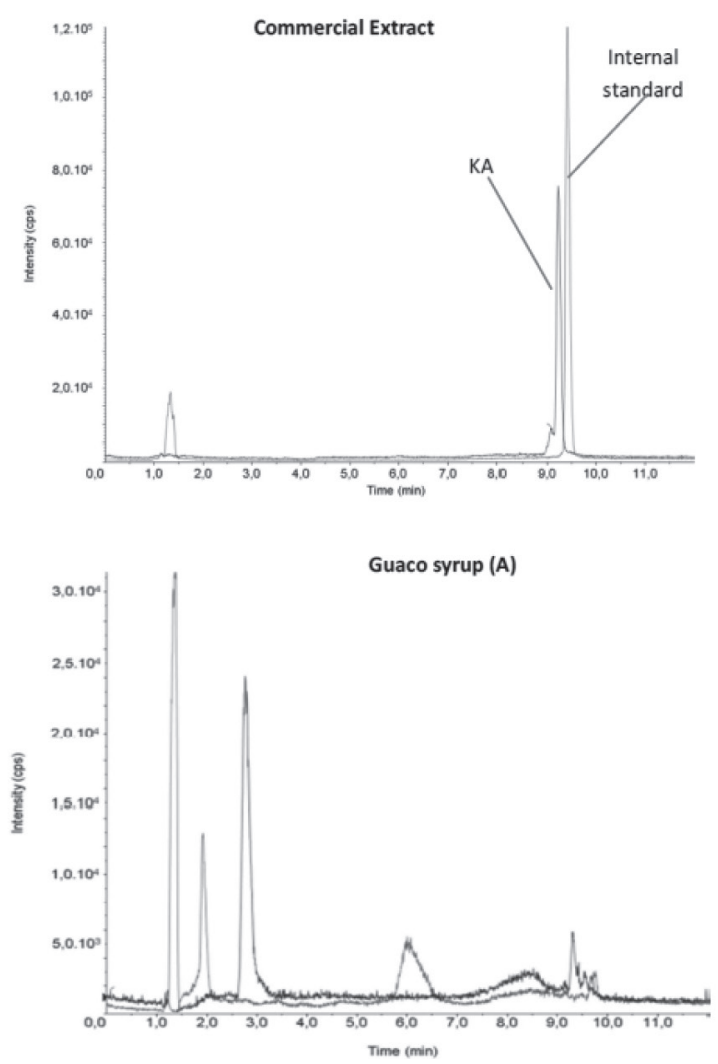

Figure 2. Chromatograms of the samples (Tincture, syrup and commercial extract) from "guaco" (M. glomerata) showing the KA and internal standard. [M-H] ion at $\mathrm{m} / \mathrm{z}, 301.00$ and 455.00 using negative XIC mode; Temperature $40{ }^{\circ} \mathrm{C}$; injection $5 \mu \mathrm{L}$; SIM mode at m/z, $301.00>301.00$ and $455.00>455.00$. The peak area of the ion intensity of the SIM mode $(301.00>301.00)$ and $(455.00>455.00)$ were indicated from independent experiments

to the absence of fragmentation mentioned, this method employed a kind of SIM mode for KA quantification. In this work, was used a pseudo MRM mode where was used the same ion in the Q1 and Q3. Miyazaki et al. ${ }^{15}$ used pseudo MRM mode to determine Kaurenoic acid in Hypnum plumaeforme. Betulinic acid, used as internal standard in present study, does not present fragmentation like Kaurenoic acid and was used pseudo MRM mode for this molecule. It was possible to solve the peaks with retention times $9.22 \mathrm{~min}$ (KA) and $9.41 \mathrm{~min}$ (internal standard), plotting different curves for each $\mathrm{m} / \mathrm{z}$, ratio. As shown in Figure 2 an example of the tincture Extracted Ion Chromatogram - XIC which represents a chromatogram of ions separate in the presence of the internal standard. Each chromatogram was individually integrated and quantitative results were obtained after evaluation from similar chromatograms. The chromatograms of all the samples were integrated for evaluation of the KA deprotonated ion at $m / z, 301.00$.

\section{Analysis of the KA content in samples of M. glomerata (guaco)}

Commercially available herbal medicines, guaco syrup A and guaco syrup $\mathbf{B}$, were analyzed after dilution of 1:10 in acetonitrile and injected in the equipment. The commercial extract and the tincture were diluted in the ratio 1:1000 using acetonitrile as solvent before being injected in the equipment. To calculate the KA concentration in each product, analytical curves were constructed with addition of the following concentrations of KA standard: $0 \mathrm{mg} \mathrm{mL}^{-1}, 0.21 \mathrm{mg} \mathrm{mL}^{-1}$, $0.64 \mathrm{mg} \mathrm{mL}^{-1}$ and $1.06 \mathrm{mg} \mathrm{mL}^{-1}$, with triplicate analysis at each point. After construction of the analytical calibration curves the concentration of KA in the tincture (tin), commercial extract (ce) and in guaco syrup (gs) was calculated according to the formulas shown in Figure 3.

$$
\begin{array}{r}
y \operatorname{tin}( \pm 0,0841)=1,65( \pm 0,0596) x+1,5348( \pm 0,0374) \\
y c e( \pm 0,0694)=1,7818( \pm 0,0492) x+0,3405( \pm 0,0309) \\
y g s( \pm 0,1081)=1,7561( \pm 0,0767) x+0,5788( \pm 0,0481)
\end{array}
$$

Figure 3. Formulas adjusted according to the Ordinary Least Squares method to calculate the concentration of $K A$ in the tincture (tin), commercial extract (ce) and in "guaco" syrup (gs)

In the guaco syrup $\mathbf{A}$, it was not possible to quantify due to the KA concentration is below the detection limit. From the equations of the adjusted curves, the KA concentrations were calculated in all the samples and the results are reported in Table 2.

Table 2. KA content in each sample and method limits

\begin{tabular}{lccc}
\hline Sample & $\begin{array}{c}\text { Content } \\
(\mathrm{mg} / \mathrm{mL})\end{array}$ & $\begin{array}{c}\text { LOD } \\
(\mathrm{mg} / \mathrm{mL})\end{array}$ & $\begin{array}{c}\text { LOQ } \\
(\mathrm{mg} / \mathrm{mL})\end{array}$ \\
\hline Tincture & $0.93( \pm 0.04)$ & $5.69 \times 10^{-5}$ & $5.69 \times 10^{-4}$ \\
Commercial Extract & $0.19( \pm 0.018)$ & $1.00 \times 10^{-4}$ & $1.00 \times 10^{-3}$ \\
Guaco syrup A & $<\mathrm{LOD}$ & - & - \\
Guaco syrup B & $3.00 \times 10^{-3}( \pm 0.00028)$ & $1.52 \times 10^{-4}$ & $1.52 \times 10^{-3}$ \\
\hline
\end{tabular}

The results presented in Table 2 show that the sample with the highest concentration of KA was the tincture, whose preparation represents an excellent method of extracting of this active principle with several pharmacological properties. The commercial extract from "guaco" showed compound content of $0.19 \mathrm{mg} \mathrm{mL}^{-1}$, five times less than in the tincture. However, in "guaco" syrup a very low content was observed, even lower than the limit of detection of the equipment for "guaco" syrup A. These results have great chemical-biological 
significance since this medicinal plant is widely used as medicine by the population in its different dosage forms. Accuracy was assessed by recovery by the standard addition method, since it is not possible to obtain the analyte-free matrix (KA). In this way, known quantities of kaurenoic acid were added in triplicate in "guaco" samples, obtaining three levels of concentration. Samples without addition of standard and addition of standard were analyzed simultaneously. The standard addition method was applied to evaluate the selectivity of this method, since it is not possible to obtain the matrix ("guaco" extract) free of kaurenoic acid. Thus, an analytical curve was performed with addition of the compound of interest (kaurenoic acid) in the matrix and compared with an analytical curve without the presence of the matrix (Figure 4).
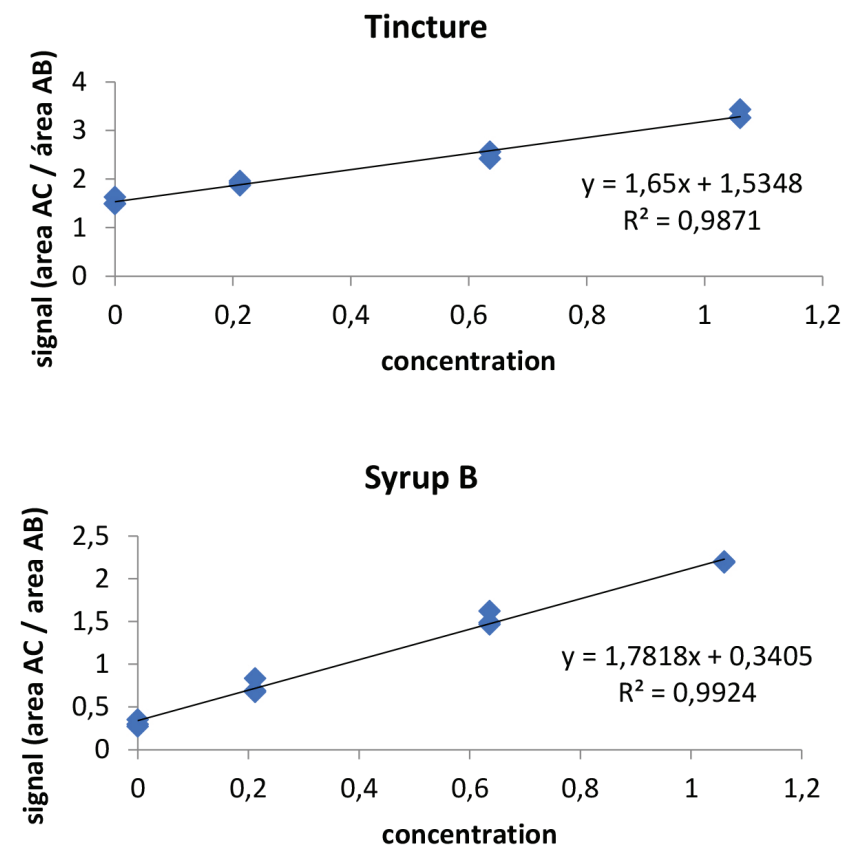

Figure 4. Calibration curve by addition of pattern in tincture and syrup B from samples "guaco"

A simple, reproducible and sensitive method was developed to KA determination in samples Mikania glomerata which may be efficiently used in the pharmaceutical industry for the quality control of this medicinal herb. The method developed in this work was suitable for detection and quantification of KA in natural products from medicinal plants. It is a simpler method to execute than the methods reported in the literature, since it does not require previous steps to prepare the sample, besides being applicable to samples of different complexities.

The main advantages of the method would be mainly the reduction of time of analysis and the generation of residues, thus going according to the principles of green chemistry. The proposal of a rapid method becomes very useful for the routine of industrial quality control, aiming at obtaining standardized herbal medicines. Thus, this method developed for kaurenoic acid determination in samples of "guaco" (extract, tincture and syrup) represents an excellent, simple, quick and efficient analytical alternative for analysis of KA in complex matrices from simple dilution and injection in the equipment.

\section{CONCLUSIONS}

Among the metabolites from natural origin with recognized medicinal properties, the kaurenoic acid diterpene stands out, one of the main bioactive constituent found in medicinal plant "guaco" (M. glomerata). The KA presenting many pharmacological activities such as antioxidant, anti-inflammatory, leishmanicide, antimicrobial, antimalarial and cytotoxic. This work describes a High Performance Liquid Chromatography coupled to triple quadrupole Mass Spectrometer detector with tandem capabilities (HPLC-QqQ-MS/ MS) method for KA determination in extract, tincture and syrup. The developed method represents an excellent alternative for agile, simple and efficient analysis of KA in complex matrices from simple dilution and injection in the equipment.

\section{ACKNOWLEDGMENTS}

The authors are grateful to CNPq, INCTBio, FAPEMIG; Rede Mineira de Química (RQ-MG) and CAPES for financial support.

\section{REFERENCES}

1. Brasil, Agência Nacional de Vigilância Sanitária, Formulário de Fitoterápicos da Farmacopéia Brasileira/Agência Nacional de Vigilância Sanitária, $1^{\text {st }}$ ed., Brasília, 2011.

2. Lúcia, D.; Moreti, C.; Fernando, L.; Moraes, S.; Rodrigues, M.; Cassio, R.; Veneziani, S.; Ricardo, S.; Paula, B.; Almeida, F.; Henrique, C.; Martins, G.; Anaerobe 2017, 47, 201.

3. Fierro, I. M.; Silva, A. C. B.; Silva, C. L.; Moura, R. S.; Barja-Fidalgo, C.; J. Ethnopharmacol. 1999, 66, 19.

4. Mourão, V. B.; Giraldi, G. M.; Mara, L.; Neves, G.; Oliveira, F.; Gaspi, D. G.; Rodrigues, A. A. A. F.; Augusto, M.; Esquisatto, M.; Ventura, M.; Vii, M.; Acta Cirurgica Bras. 2014, 29, 30.

5. Cavalcanti, B. C.; Costa-Lotufo, L. V.; Moraes, M. O.; Burbano, R. R.; Silveira, E. R.; Cunha, K. M. A.; Rao, V. S. N.; Moura, D. J.; Rosa, R. M.; Henriques, J. A. P.; Pessoa, C.; Food Chem. Toxicol. 2006, 44, 388.

6. Coll Aráoz, M. V.; Mercado, M. I.; Grau, A.; Catalán, C. A. N.; Biochem. Syst. Ecol. 2010, 38, 1042.

7. da Silva, R. Z.; da Silva, M. Z.; Leal, L. D. F.; Yunes, R.; Miguel, O.; Cechinel-Filho, V.; Visão Acadêmica 2002, 3, 59.

8. Miranda, M. M.; Panis, C.; da Silva, S. S.; Macri, J. A.; Kawakami, N. Y.; Hayashida, T. H.; Madeira, T. B.; Acquaro Jr., V. R.; Nixdorf, S. L.; Pizzatti, L.; Ambrósio, S. R.; Cecchini, R.; Arakawa, N. S.; Verri Jr., W. A.; Costa, I. C.; Pavanelli, W. R.; Mediators Inflammation 2015.

9. de Santos, J. O.; Pereira, G. R.; Brandão, G. C.; Borgati, T. F.; Arantes, L. M.; de Paula, R. C.; Soares, L. F.; do Nascimento, M. F. A.; Ferreira, M. R. C.; Taranto, A. G.; Varotti, F. P.; de Oliveira, A. B.; J. Braz. Chem. Soc. 2016, 27, 551.

10. Soares, A. C. F.; Matos, P. M.; da Silva, K. F. D.; Martins, C. H. G.; Veneziani, R. C. S.; Ambrósio, S. R.; Dias, H. J.; dos Santos, R. A.; Heleno, V. C. G.; J. Braz. Chem. Soc. 2019, 30, 333.

11. Yang, Y. L.; Chang, F. R.; Wu, C. C.; Wang, W. Y.; Wu, Y. C.; J. Nat. Prod. 2002, 65, 1462.

12. Bresciani, L. F. V.; Yunes, R. A.; Burger, C.; Oliveira, L. E.; Bóf, K. L.; Cechinel-Filho, V.; Z. Naturforsch. C 2004, 59, 229.

13. Bertolucci, S. K. V.; Pereira, A. B. D.; Pinto, J. E. B. P.; Ribeiro, J. A. D. A.; de Oliveira, A. B.; Braga, F. C.; Planta Med. 2009, 75, 280.

14. Czelusniak, K. E.; Brocco, A.; Pereira, D. F.; Freitas, G. B. L.; Rev. Bras. Plantas Med. 2012, 14, 400.

15. Miyazaki, S.; Kimura, H.; Natsume, M.; Asami, T.; Hayashi, K. I.; Kawaide, H.; Nakajima, M.; Biochem. Biophys. Rep. 2015, 2, 103. 